ARTICLE

Received 1 Oct 2013 | Accepted 14 Oct 2013 | Published 12 Nov $2013 \quad$ DOl: 10.1038/ncomms3761

\title{
Efficient organometal trihalide perovskite planar-heterojunction solar cells on flexible polymer substrates
}

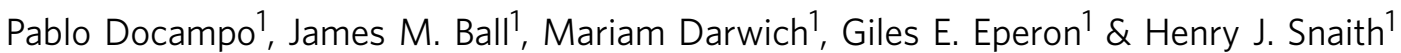

Organometal trihalide perovskite solar cells offer the promise of a low-cost easily manufacturable solar technology, compatible with large-scale low-temperature solution processing. Within 1 year of development, solar-to-electric power-conversion efficiencies have risen to over $15 \%$, and further imminent improvements are expected. Here we show that this technology can be successfully made compatible with electron acceptor and donor materials generally used in organic photovoltaics. We demonstrate that a single thin film of the lowtemperature solution-processed organometal trihalide perovskite absorber $\mathrm{CH}_{3} \mathrm{NH}_{3} \mathrm{Pbl}_{3-\mathrm{x}} \mathrm{Cl}_{\mathrm{x}}$, sandwiched between organic contacts can exhibit devices with power-conversion efficiency of up to $10 \%$ on glass substrates and over $6 \%$ on flexible polymer substrates. This work represents an important step forward, as it removes most barriers to adoption of the perovskite technology by the organic photovoltaic community, and can thus utilize the extensive existing knowledge of hybrid interfaces for further device improvements and flexible processing platforms.

\footnotetext{
${ }^{1}$ Clarendon Laboratory, University of Oxford, Parks Road, Oxford OX1 3PU, UK. Correspondence and requests for materials should be addressed to H.J.S. (email: h.snaith1@physics.ox.ac.uk)
} 
P hotovoltaic uptake has been growing rapidly to make use of the world's most abundant energy source, sunlight. Historically, conventional photovoltaics, namely crystalline silicon (c-Si), have been very expensive and this has led to a burgeoning field of research in solar technologies fabricated from fundamentally low-cost materials employing fundamentally lowcost fabrication methods ${ }^{1-5}$. Among these, the lowest cost and highest throughput method of fabrication is solution based reelto-reel printing 6 . However, this has to be balanced with materials costs, other expenses such as environmental barrier protection and yield achievable when fabricating thin-film solar technologies at a high rate on flexible and deformable substrates.

Over the last 5 years, there has been a continued downward drop in the price of $\mathrm{c}-\mathrm{Si}$ solar cells to a level where the price of electricity from solar photovoltaics may have achieved grid parity in some parts of the world ${ }^{7}$. It is hence hard to envisage a solar technology breaking into the large-scale power market unless it can compete closely with c-Si on efficiency and then beat it on price. Thin-film solar cells, which are generally fabricated from vapour deposition of a solid semiconductor absorber film sandwiched between charge selective contacts, are slowly approaching the efficiencies of c-Si. However, the three most successful technologies, copper indium gallium (di) selenide, copper indium sulphide and cadmium telluride, all require deposition at relatively high temperature $\left(\sim 500^{\circ} \mathrm{C}\right)$ and carefully controlled post deposition thermal treatments. This significantly limits the choice of possible substrates to those compatible with higher temperatures, and inhibits the possibilities of processing multiple cells on top of each other, required for high efficiency multi-junction device architectures. In contrast, organic photovoltaics can be processed very easily at low temperature, and has thus been able to capitalize upon the multi-junction approach to achieve efficiencies of over $10 \%{ }^{8,9}$. However, in order to match c-Si on efficiency, organics still require at present a number of revolutionary step improvements in performance and device operation.

Organometal trihalide perovskite absorbers are an appealing alternative photovoltaic technology, as they seem to combine the most appealing aspects of both thin film and organics: They can be processed under $150^{\circ} \mathrm{C}$, are fully solid-state and already exhibit high power-conversion efficiencies of between 12-15\% when integrated into meso-superstructured solar cells (MSSC), 10,11 or perovskite-sensitized solar cells ${ }^{12,13}$. We have also very recently demonstrated their use in conventional vapor-deposited thin-film planar-heterojunction architectures, with over $15 \%$ efficiency ${ }^{14}$.
Here, we demonstrate that the $\mathrm{CH}_{3} \mathrm{NH}_{3} \mathrm{PbI}_{3-\mathrm{x}} \mathrm{Cl}_{\mathrm{x}}$ perovskite absorber can be processed from solution, sandwiched between the conventional charge collection layers and electrode configuration for organic photovoltaic diodes. We demonstrate that a device structure consisting of fluorine-doped tin oxide (FTO)-coated glass, poly(3,4-ethylenedioxythiophene) poly(styrenesulphonate) (PEDOT:PSS), the perovskite absorber, [6,6]-phenyl- $\mathrm{C}_{61}$-butyric acid methyl (PCBM), $\mathrm{TiO}_{x}$ and aluminium, (FTO/PEDOT:PSS/ $\mathrm{CH}_{3} \mathrm{NH}_{3} \mathrm{PbI}_{3-\mathrm{x}} \mathrm{Cl}_{\mathrm{x}} / \mathrm{PCBM} / \mathrm{TiO}_{x} / \mathrm{Al}$ ), as a planar heterojunction can deliver up to $10 \%$ power-conversion efficiency (PCE), and up to $6.5 \%$ for the same configuration on an indium-doped tin oxide (ITO)-coated plastic foil. This demonstrates the versatility of the perovskite absorber layer and indicates that the broader activities around organic photovoltaics can be applied towards the perovskite solar cell technology, greatly enhancing its potential to achieve over $20 \%$ efficiencies ${ }^{15}$ and thus compete with the established c-Si industry. Furthermore, the structure developed in this work utilizes a p-contact to the FTO/glass substrate, thus leading towards the possible application of this technology in hybrid tandem solar cells, where the bottom cell is based on existing copper indium sulphide or c-Si technologies ${ }^{16}$.

\section{Results}

Device structure. We have recently reported on perovskite-based thin-film photovoltaic devices with an architecture evolved from the solid-state dye-sensitized solar cells, where holes are collected through the metal cathode and electrons through the FTO anode $^{10}$. In this configuration, a thin film of mesoporous alumina is deposited over compact $\mathrm{TiO}_{2}$-covered FTO substrates to aid the perovskite film formation ${ }^{10}$, then an organic hole transporter is deposited over the formed structure to provide a hole selective contact. Henceforth, this configuration will be referred to as 'regular' and the cell architecture, which represents the focus of the work here shall be termed 'inverted'. Typical materials used in organic photovoltaics as hole selective contacts are PEDOT:PSS, $\mathrm{V}_{2} \mathrm{O}_{5}$ and $\mathrm{NiO}^{17,18}$, while usually PCBM and more recently poly[ $\left(9,9\right.$-bis $\left(3^{\prime}\right.$-( $N, N$-dimethylamino)propyl)-2,7-fluorene)-alt$2,7-(9,9-$ dioctylfluorene $)](\mathrm{PFN})^{19}$ are used as electron acceptors or electron selective contacts. In order to determine whether these materials are compatible to act as electron and hole acceptors within the perovskite-based devices, we first estimate photoluminescence (PL) quenching of the perovskite emission in thin-film bi-layers, as has become routine in all organic solar cells $^{20}$. We present this data in Fig. 1 and the results are summarized in Table 1 . All the $p$-type layers chosen in this work
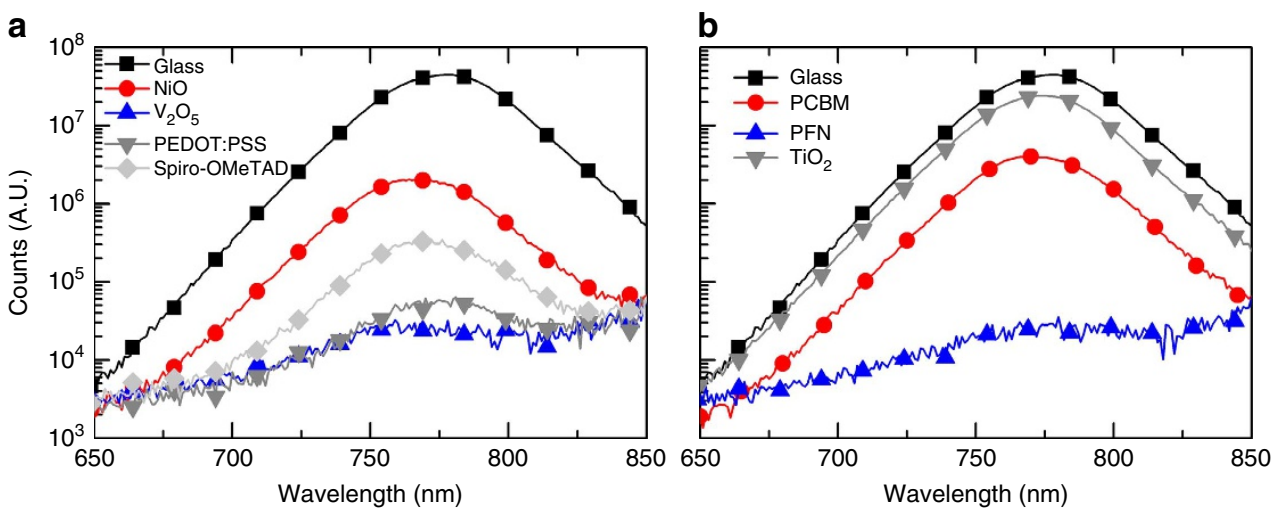

\footnotetext{
Figure 1 | Photoluminescence response for $\mathrm{CH}_{3} \mathrm{NH}_{3} \mathrm{Pbl}_{3-\mathrm{x}} \mathrm{Cl}_{x}$ perovskite films coated with $p$ - and $n$-type layers to ascertain their charge transfer compatibility. (a) Steady-state photoluminescence spectra of $p$-type quenchers and (b) $n$-type quenchers of perovskite films processed in a bi-layer configuration. For the $p$-type quenchers, the perovskite was coated on top of the $p$-type collection layers, whereas for the $n$-type quenchers, the perovskite was first processed on glass slides, then the $n$-type charge collection layers were spin coated on top. Perovskite excitation at $530 \mathrm{~nm}$ was performed from the opposite side of the quencher.
} 
quench the perovskite steady-state PL more efficiently than the archetypal $2,2^{\prime}, 7,7^{\prime}$-Tetrakis[ $N, N$-di(4-methoxyphenyl)amino]9,9'-spirobifluorene (spiro-OMeTAD) p-type hole conductor previously employed in the MSSCs, with similar values for PEDOT:PSS and $\mathrm{V}_{2} \mathrm{O}_{5}$ of $99.8 \%$ quenching efficiency. All the $n$-type layers exhibit significantly higher quenching rates than the $\mathrm{TiO}_{2}$ compact layers previously employed. Our observation of enhanced PL quenching with PCBM, is consistent with our previous work where we looked at electron transfer from the perovskite absorber to fullerene self-assembled monolayers, indicating that organic electron and hole acceptors are highly effective when interfaced with the perovskite absorbers ${ }^{21}$. All the cells fabricated in this work utilize a spin coated PCBM layer as the $n$-type contact, since solar cells fabricated with a PFN interlayer yielded an extremely poor photovoltaic performance.

When applied to devices, $\mathrm{NiO}$ and $\mathrm{V}_{2} \mathrm{O}_{5}$ p-type layers resulted in rather poor photovoltaic performance (Supplementary Fig. S1), showing signs of high series resistance and for $\mathrm{V}_{2} \mathrm{O}_{5}$ a low shunt resistance in the $J-V$ curves. This is likely to arise in part from extremely poor perovskite film formation upon the substrate, with very poor surface coverage (Supplementary Fig. S2). This will enable direct contact of the PCBM $n$-type layer with the $p$-type metal oxide, presenting a shunting path. In addition, the high series resistance may arise from low conductivity of the $p$-type oxide, suggesting improvements could be made by controlling the conductivity or doping density in the $p$-type oxide, and improving the film formation of the perovskite upon the flat metal oxide layers. In contrast, when a thin PEDOT:PSS layer is used as the $p$-type contact, a solid perovskite absorber

\section{Table 1 | Steady-state photoluminescence quenching efficiency.}

p-type layers

$\mathrm{NiO}$

$\mathrm{V}_{2} \mathrm{O}_{5}$

PEDOT:PSS

Spiro-OMeTAD

The photoluminescence quenching from the perovskite was quantified for both $p$ - and $n$-typ charge collection layers contacting the perovskite absorber. The quenching efficiency was calculated by integrating the photoluminescence spectra over wavelength and comparing with the neat perovskite layer. We note that this is not measured in an integrating sphere, so only represents an estimation of the quenching efficiency. layer exhibiting over $95 \%$ surface coverage is achieved, as estimated from scanning electron microscopy (SEM) images, and the conductivity of the PEDOT:PSS is controlled and high. This results in good photovoltaic properties when a bi-layer of PCBM and compact $\mathrm{TiO}_{x}$ is employed as the $n$-type charge collection layer. The origin of the different perovskite film formation characteristics on the different $p$-type layers is not completely understood at this moment and will be the subject of a future study, but is likely to originate from differences in surface roughness and perovskite/surface interaction energy ${ }^{22}$. To be able to process these structures in air, the top interlayer of $\mathrm{TiO}_{x}$ was necessary to achieve a stable electronic contact with the top $\mathrm{Al}$ anode (Supplementary Fig. S3) ${ }^{23}$. A cross-sectional SEM image of an optimized device is presented in Fig. 2.

Photovoltaic performance. We show the photovoltaic performance of the inverted device structure in comparison with that of the regular MSSC device architecture (composed of a compact $\mathrm{TiO}_{2}$ electron accepting layer, low temperature processed mesoporous alumina film filled with perovskite absorber and spiroOMeTAD as the hole transporting layer) in Fig. 3. The best performing device with the inverted architecture achieved a short-circuit photo current approaching $16 \mathrm{~mA} \mathrm{~cm}^{-2}$, open-circuit voltages of over $0.9 \mathrm{~V}$ and $9.8 \%$ PCE, closely matching initial reports with devices based on the standard architecture. We also stress that this is achieved in a planar configuration, where no nanostructured scaffold is present and the total active layer thickness is around $300 \mathrm{~nm}$. This good operation of the solid perovskite layer is consistent with our recent results where a planar heterojunction of a similar thickness composed of $\mathrm{TiO}_{2} /$ $\mathrm{CH}_{3} \mathrm{NH}_{3} \mathrm{PbI}_{3-\mathrm{x}} \mathrm{Cl}_{\mathrm{x}} /$ Spiro-OMeTAD delivered over $15 \% \mathrm{PCE}^{14}$. The PCE value shown here for inverted perovskite solar cells is higher than the best published single junction organic solar cells ${ }^{19,24}$, similar to the highest efficiencies for a-Si, and compares favourably with early reports of alternative thin-film technologies such as copper indium gallium (di) selenide, cadmium telluride ${ }^{25}$, with significant further improvements expected in the very near future ${ }^{15}$. A histogram for the PCE of a set of around 40 devices is also shown in Supplementary Fig. S4 as well as the photovoltaic performance of an inverted device under a series of light intensities from full AM 1.5 sunlight conditions to low $<1 \%$ sunlight irradiation in Supplementary Fig. S5.

It is important to note that the $J-V$ curves presented in this work were measured after aging the samples under constant light a

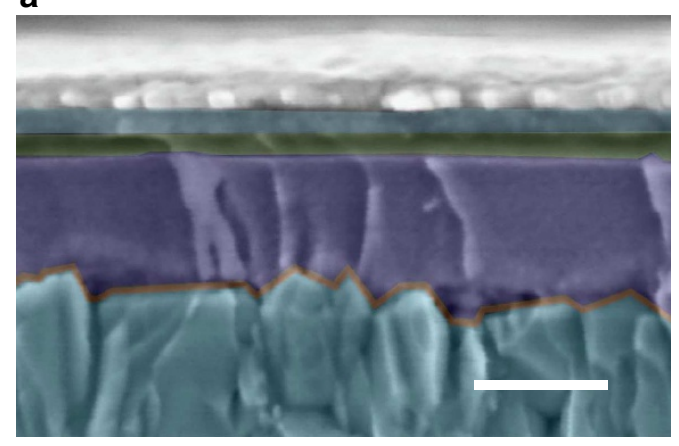

b

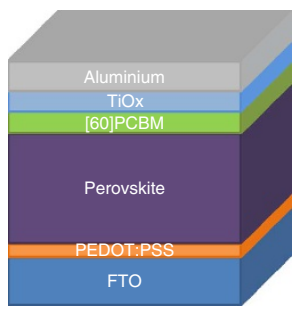

C

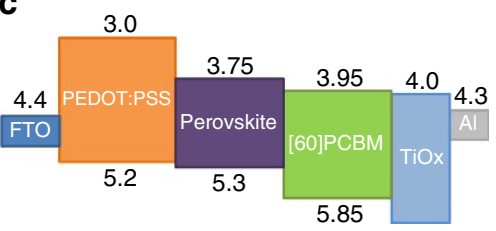

Figure 2 | Optimized device structure. (a) SEM. cross-sectional image of the optimized inverted device configuration. Scale bar represents 250 nm. The different layers have been tinted with the colour scheme of the device schematic shown in (b). (c) Approximate energy band diagram of the fabricated inverted structure taken from reference ${ }^{21}$. 

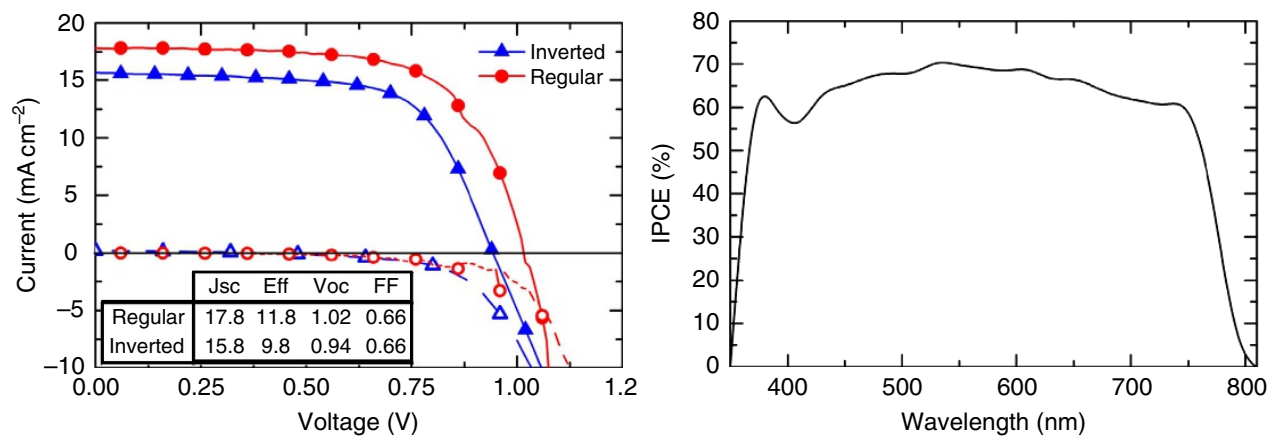

Figure 3 | Photovoltaic performance characteristics. (a) Current voltage curves for champion devices of regular MSSC (red circles) and inverted planar-heterojunction (blue triangles) configuration. Inset shows the short-circuit current density $\left(J_{\mathrm{sc}}, \mathrm{mA} \mathrm{cm}^{-2}\right)$, power-conversion efficiency (Eff, \%), open-circuit voltage $\left(V_{\mathrm{oc}}, \mathrm{V}\right)$ and $\mathrm{FF}$ for both device architectures. (b) Incident photon-to-electron conversion efficiency against wavelength for a typical inverted device. The integrated current from the product of the incident photon-to-electron conversion efficiency and the $\mathrm{AM} 1.5100 \mathrm{~mW} \mathrm{~cm}{ }^{-2}$ solar spectrum is $16.5 \mathrm{~mA} \mathrm{~cm}^{-2}$, in close agreement to the short-circuit photocurrent measured under simulated sunlight.
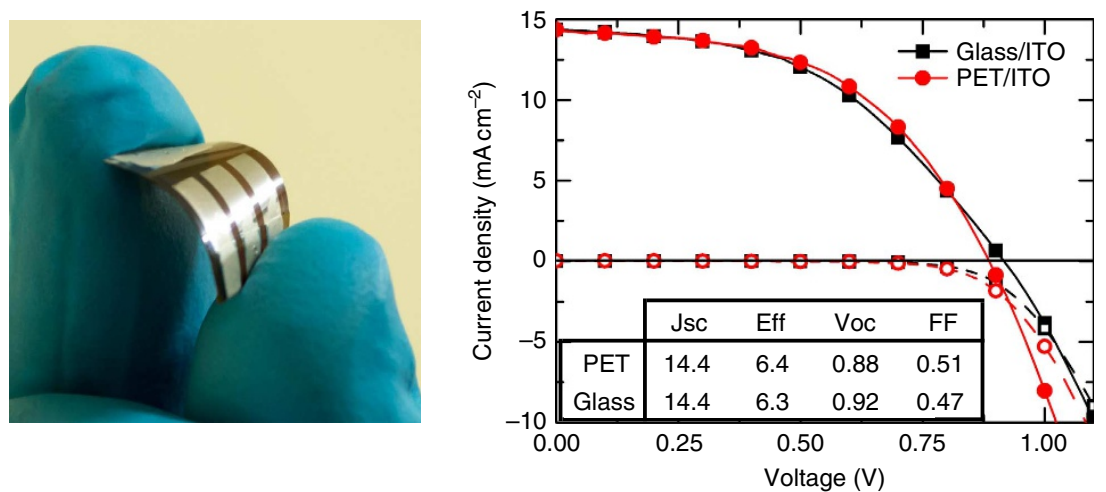

Figure 4 | Flexible solar cell performance. (a) Picture of the first flexible perovskite solar cell and (b) $J-V$ curves for inverted architecture devices fabricated both on ITO-covered glass and PET, measured under-simulated AM $1.5100 \mathrm{~mW} \mathrm{~cm}^{-2}$ sunlight. The inset table shows the photovoltaic performance parameters, $J_{\mathrm{sc}}\left(\mathrm{mA} \mathrm{cm}^{-2}\right)$, efficiency $(\%), V_{\mathrm{oc}}(\mathrm{V})$ and $\mathrm{FF}$.

illumination for a number of minutes. The initial current voltage curve typically exhibit a little over $>1 \%$ PCE, but increased to between $7.5-10 \%$ after around 10 minutes of constant illumination and operation in air (Supplementary Fig. S6). This is not the case for the regular MSSC that operates well immediately. The requirement for light soaking of $\mathrm{TiO}_{x}$ is consistent with previous reports in organic photovoltaics ${ }^{26}$.

Flexible solar cells. Finally, enabled by the 'all low-temperature' processing, we have also fabricated inverted perovskite devices on ITO-coated poly(ethylene terephthalate) (PET) substrates, shown in Fig. 4. Devices fabricated on either ITO-covered glass or PET exhibited essentially the same photovoltaic performance parameters, with short-circuit currents of over $14 \mathrm{~mA} \mathrm{~cm}^{-2}$, opencircuit voltages of around $0.9 \mathrm{~V}$ and power-conversion efficiencies of over $6.3 \%$. The main difference between devices fabricated on ITO- and FTO-covered glass is the lower fill factor (FF) and current of the ITO devices. This may in part be accommodated by the batch-to-batch variation, but is likely to also arise from poorer perovskite film formation and lower surface coverage upon the PEDOT:PSS-coated ITO as opposed to the PEDOT:PSS-coated FTO, as shown in Supplementary Fig. S7. The main difference between FTO and ITO is the surface roughness, with the latter being much smoother. It is likely that the roughness of the FTO is an important factor in enabling more uniform perovskite coating and ensuing better operation of these inverted perovskite solar cells, which do not incorporate any mesoporous scaffold.

\section{Discussion}

The loss in PCE of $10 \%$ for the inverted devices as compared with $11.8 \%$ for the regular architecture arises from their slightly lower FF, short-circuit current and voltage. One of the key differences between our fabrication protocols for these two device architectures is that the compact $\mathrm{TiO}_{2}$ layer is annealed to $500{ }^{\circ} \mathrm{C}$ in the regular MSSC. In order to check whether this could affect device performance, we have fabricated regular MSSCs with nonsintered compact $\mathrm{TiO}_{x}$ layers. We observe the same requirement for light soaking as described in the photovoltaic performance subsection, and the same significant reduction in all photovoltaic performance parameters, especially FF (Supplementary Fig. S8). This leads us to conclude that the presented inverted perovskite solar cell architecture should be capable of attaining the same efficiencies as the best performing MSSCs once a suitably effective $\mathrm{TiO}_{x}$ or air stable $n$-type collection layer is employed.

Another striking difference between the MSSCs and the presented inverted architecture is that in the former case, a mesoporous scaffold is used for the formation of the perovskite absorber, which presumably results in a structure where both perovskite and hole transporter are in close contact allowing efficient charge separation over short distances. In the inverted configuration presented here, a planar heterojunction is used. 
This implies that the majority of excitons or charges that are generated at/near the bottom of the device must travel the whole film thickness in order to be collected at the top contact. We have shown previously that this planar configuration also results in better performing solar cells when the perovskite film is deposited through a dual source vacuum deposition technique ${ }^{14}$, and is thus of a significant interest for future technology developments.

In the optimization of the inverted solar cells, we fabricated devices with a range of perovskite thicknesses, from $100 \mathrm{~nm}$ up to $900 \mathrm{~nm}$ (Supplementary Figs S9-S11). We obtained the best results with films of $300-400 \mathrm{~nm}$, which absorb approximately $90 \%$ of the light that passes through the FTO-coated glass, integrated between $350-750 \mathrm{~nm}$, taking into account the extended optical path length due to the presence of the $\mathrm{Al}$ 'mirror' as the top contact (Supplementary Fig. S10). Devices fabricated from films of over $600 \mathrm{~nm}$ in thickness absorb more than $99 \%$ of the incident light; however, we found that the short-circuit currents for these thicker devices drop, and power-conversion efficiencies are maximized at around $400 \mathrm{~nm}$ thickness. As the exciton binding $\left(\mathrm{E}_{\mathrm{b}}\right)$ energy is expected to be on the order of but slightly larger than the thermal energy $\left(\mathrm{E}_{\mathrm{b}} \sim 45 \mathrm{meV}\right)$ (ref.27), we expect a coexistence of excitons and free charge. At this stage, we do not know the branching ratio between free carriers and bound excitons, but this is an important factor to determine in order to understand the operating mechanism of these planarheterojunction solar cells. The observed thickness dependence of the photocurrent sets a lower limit to the electron and hole diffusion lengths, whether they are excitons or free charge, of at least $400 \mathrm{~nm}$ in this mixed halide perovskite absorber.

With the rapidly approaching commercial efficiencies and the tremendous versatility of the perovskite absorber demonstrated here, some concerns exist over potential toxicology issues of $\mathrm{Pb}$ in the current generations of organometal trihalide perovskites. However, thorough lifecycle analysis is required to correctly assess the scale of this issue, and the overall balance between the power generated from $\mathrm{Pb}$-based $\mathrm{PV}$ and what pollution and toxic contamination is offset by such must be made. In addition, the perovskite-based solar cell technology is very young and a number of groups have already begun research to replace $\mathrm{Pb}$ with less toxic elements, which we can expect to lead to fruitful results in the near future ${ }^{15,28}$.

In summary, organometallic perovskite solar cells offer the promise of a low-cost, mass-manufacturable solar technology that is compatible with current large-scale printing infrastructure. In this work, we have employed the ambipolar perovskite $\mathrm{CH}_{3} \mathrm{NH}_{3} \mathrm{PbI}_{3-\mathrm{x}} \mathrm{Cl}_{x}$, demonstrating fully air- and low-temperature processed solar cells exhibiting full sun power-conversion efficiencies approaching $10 \%$. In doing so, we have demonstrated an 'inverted' architecture for perovskite-based photovoltaics where holes are efficiently collected from the FTO substrate through a PEDOT:PSS layer, and electrons from the top anode through a PCBM layer. We find that PEDOT:PSS functions as an excellent hole acceptor in this inverted system. The work presented here offers a new approach to design architecture for perovskite-based solar cells and is manufacturable on a broad range of substrates, including flexible plastic foils. In one sense, this demonstrates the versatility of the perovskite thin-film technology to the broad variety of possible device configurations, and equally importantly, this removes most barriers to adoption of the perovskite technology by the organic- and solutionprocessed photovoltaic community.

\section{Methods}

Substrate preparation. FTO-coated glass sheets $(7 \Omega / \square$ Pilkington) were etched with zinc powder and $\mathrm{HCl}(2 \mathrm{M})$ to obtain the required electrode pattern. The sheets were then washed with soap ( $2 \%$ Hellmanex in water), de-ionized water, acetone and methanol and finally treated under an oxygen plasma for $5 \mathrm{~min}$ to remove the last traces of organic residues.

$\mathrm{TiO}_{\boldsymbol{x}}$ flat film precursor solution. The $\mathrm{TiO}_{x}$ flat film precursor solution consists of $0.23 \mathrm{M}$ titanium isopropoxide (Sigma-Aldrich, $99.999 \%$ ) and $0.013 \mathrm{M} \mathrm{HCl}$ solution in isopropanol ( $>99.9 \%$ Fisher Chemicals). To prepare this solution, titanium isopropoxide $(369 \mu \mathrm{l})$ was diluted in isopropanol $(2.53 \mathrm{ml})$ at $0.46 \mathrm{M}$. Separately, a $2 \mathrm{M} \mathrm{HCl}$ solution $(35 \mu \mathrm{l})$ was diluted down with isopropanol $(2.53 \mathrm{ml})$ to achieve a $0.026 \mathrm{M}$ concentration. Finally, the acid-containing solution was added dropwise to the titanium precursor solution under heavy stirring. The solution was filtered with a PTFE filter with $0.2 \mu \mathrm{m}$ pore size before use.

Regular MSSC architecture fabrication. The etched FTO substrates were coated with a compact layer of $\mathrm{TiO}_{2}$ deposited by spin coating the $\mathrm{TiO}_{x}$ flat film precursor solution at 2,000 r.p.m. for $60 \mathrm{~s}$ and consequently heating at $500{ }^{\circ} \mathrm{C}$ for $30 \mathrm{~min}$. Then the mesostructured scaffold was deposited by spin coating a colloidal dispersion of $\sim 20 \mathrm{~nm} \mathrm{Al}_{2} \mathrm{O}_{3}$ nanoparticles in isopropanol, followed by drying at $150{ }^{\circ} \mathrm{C}$ for $10 \mathrm{~min}$. After cooling down to room temperature, the perovskite was deposited by spin coating from a DMF solution of methylammonium iodide and $\mathrm{PbCl}_{2}$ (3:1 molar ratio), as described elsewhere ${ }^{11}$, which formed the perovskite after heating to $100^{\circ} \mathrm{C}$ for $45 \mathrm{~min}$ in an oven. The hole transport layer was deposited by spin coating a $7 \mathrm{vol} \%$ spiro-OMeTAD solution in chlorobenzene with added $80 \mathrm{mM}$ tert-butylpyridine and $25 \mathrm{mM}$ lithium bis(trifluoromethanesulphonyl)imide at 1,000 r.p.m. for 45 s. Finally, devices were completed with evaporation in a high vacuum of $\mathrm{Ag}$ contact electrodes through a shadow mask.

Inverted architecture fabrication. The etched FTO substrates and ITO-covered glass and PET substrates were coated with a thin film of PEDOT:PSS deposited by spin coating a 25:75 vol\% solution of PEDOT:PSS (Clevios):isopropanol ( $>99.9 \%$, Fisher Chemicals), which was sonicated in an ultrasonic bath for $15 \mathrm{~min}$ and filtered with a $2.7 \mu \mathrm{m}$ glass fibre filter before every use, at 2,000 r.p.m. for $60 \mathrm{~s}$ and subsequently annealed at $150^{\circ} \mathrm{C}$ for $20 \mathrm{~min}$ (flexible substrates were mounted on a glass slide for spin coating). After cooling down, the perovskite precursor solution was spin coated at 2,000 r.p.m. for $20 \mathrm{~s}$, and it was then heated to $100^{\circ} \mathrm{C}$ for $45 \mathrm{~min}$ in an oven to form and crystallize the perovskite absorber. The electron selective contact was deposited by spin coating a $20 \mathrm{mg} \mathrm{ml}^{-1}$ solution of $\mathrm{PC}_{60} \mathrm{BM}$ in chlorobenzene (Anhydrous, Sigma-Aldrich) at 1,000 r.p.m. for 45 s. $\mathrm{The}^{\mathrm{TiO}}{ }_{x}$ flat film precursor solution was then spin coated at 3,000 r.p.m. for $45 \mathrm{~s}$ and the films were annealed at $130{ }^{\circ} \mathrm{C}$ for $10 \mathrm{~min}$. Finally, devices were completed with evaporation in a high vacuum of $\mathrm{Al}$ contact electrodes through a shadow mask.

NiO film deposition. The spin coating precursor for the $\mathrm{NiO}$ thin film was prepared by dissolving nickel acetate tetrahydrate and monoethanolamine in ethanol, both at $0.1 \mathrm{M}$ concentration under stirring in a sealed vial in air on a hotplate at $70^{\circ} \mathrm{C}$ for $4 \mathrm{~h}$. The solution appeared homogenous and deep green. The solution was then spin coated at 2,000 r.p.m. for $45 \mathrm{~s}$, directly on the FTO/glass substrate, and was further calcined at $500{ }^{\circ} \mathrm{C}$ for $45 \mathrm{~min}$.

$\mathbf{V}_{\mathbf{2}} \mathbf{O}_{\mathbf{5}}$ film deposition. The etched FTO substrates were coated with a thin film of $\mathrm{V}_{2} \mathrm{O}_{5}$ deposited by spin coating a 1:35 vol\% solution of vanadium $(\mathrm{V})$ oxytriisopropoxide (Sigma-Aldrich) in isopropanol and subsequently heated to $500^{\circ} \mathrm{C}$ to obtain crystalline vanadium oxide layers. The solution was then spin coated at 2,000 r.p.m. for $45 \mathrm{~s}$, directly on the FTO/glass substrate, and was further calcined at $500^{\circ} \mathrm{C}$ for $45 \mathrm{~min}$.

Measurement and characterization. Solar-simulated AM 1.5 sunlight was generated with an ABET class $A A B$ solar simulator calibrated to give $100 \mathrm{~mW} \mathrm{~cm}^{-2}$ using an NREL-calibrated KG5-filtered silicon reference cell. The spectral mismatch factor was calculated to be less than $1 \%$. The $J-V$ curves were recorded with a Keithley 2400 . The active area of the solar cells was defined with a metal aperture mask of about $0.08 \mathrm{~cm}^{2}$.

Steady-state PL measurements were taken using an automated spectrofluorometer (Fluorolog, Horiba Jobin-Yvon), with a $450 \mathrm{~W}$ xenon lamp excitation source and a photomultiplier tube detector. All spectra were corrected for instrumental response using a calibration lamp of known emissivity.

SEM images were obtained using a Hitachi S-4300 microscope.

\section{References}

1. Mitzi, D. B. et al. A high-efficiency solution-deposited thin-film photovoltaic device. Adv. Mater. 20, 3657-3662 (2008).

2. Todorov, T. \& Mitzi, D. B. Direct liquid coating of chalcopyrite light-absorbing layers for photovoltaic devices. Eur. J. Inorg. Chem. 2010, 17-28 (2010).

3. Tang, J. et al. Colloidal-quantum-dot photovoltaics using atomic-ligand passivation. Nat. Mater. 10, 765-771 (2011).

4. O’Regan, B. \& Gratzel, M. A low-cost, high-efficiency solar cell based on dyesensitized colloidal tio2 films. Nature 353, 737-740 (1991). 
5. Bach, U. et al. Solid-state dye-sensitized mesoporous tio2 solar cells with high photon-to-electron conversion efficiencies. Nature 395, 583-585 (1998).

6. Krebs, F. C., Tromholt, T. \& Jorgensen, M. Upscaling of polymer solar cell fabrication using full roll-to-roll processing. Nanoscale 2, 873-886 (2010).

7. Bazilian, M. et al. Re-considering the economics of photovoltaic power. Renew. Ener. 53, 329-338 (2013).

8. Li, W., Furlan, A., Hendriks, K. H., Wienk, M. M. \& Janssen, R. A. J. Efficient tandem and triple-junction polymer solar cells. J. Am. Chem. Soc. 135, 5529$5532(2013)$

9. You, J. et al. A polymer tandem solar cell with $10.6 \%$ power conversion efficiency. Nat. Commun. 4, 1446 (2013).

10. Ball, J. M., Lee, M. M., Hey, A. \& Snaith, H. Low-temperature processed mesosuperstructured to thin-film perovskite solar cells. Energy Environ. Sci. 6, 1739-1743 (2013)

11. Lee, M. M., Teuscher, J., Miyasaka, T., Murakami, T. N. \& Snaith, H. J. Efficient hybrid solar cells based on meso-superstructured organometal halide perovskites. Science 338, 643-647 (2012).

12. Noh, J. H., Im, S. H., Heo, J. H., Mandal, T. N. \& Seok, S. I. Chemical management for colorful, efficient, and stable inorganic-organic hybrid nanostructured solar cells. Nano Lett. 13, 1764-1769 (2013).

13. Kim, H.-S. et al. Lead iodide perovskite sensitized all-solid-state submicron thin film mesoscopic solar cell with efficiency exceeding 9\%. Sci. Rep. 2, 591 (2012).

14. Liu, M., Johnston, M. B. \& Snaith, H. J. Efficient planar heterojunction perovskite solar cells by vapour deposition. Nature 501, 395-398 (2013).

15. Park, N-G. Organometal perovskite light absorbers toward a $20 \%$ efficiency low-cost solid-state mesoscopic solar cell. J. Phys. Chem. Lett. 4, 2423-2429 (2013).

16. Beiley, Z. M. \& McGehee, M. D. Modeling low cost hybrid tandem photovoltaics with the potential for efficiencies exceeding 20\%. Energy Environ. Sci. 5, 9173-9179 (2012).

17. Wang, H.-Q., Li, N., Guldal, N. S. \& Brabec, C. J. Nanocrystal $\mathrm{v}_{2} \mathrm{O}_{5}$ thin film as hole-extraction layer in normal architecture organic solar cells. Org. Electron. 13, 3014-3021 (2012).

18. Manders, J. R. et al. Solution-processed nickel oxide hole transport layers in high efficiency polymer photovoltaic cells. Adv. Funct. Mater. 23, 2993-3001 (2013).

19. He, Z. et al. Enhanced power-conversion efficiency in polymer solar cells using an inverted device structure. Nat. Photon 6, 591-595 (2012).

20. Ginger, D. S. \& Greenham, N. C. Photoinduced electron transfer from conjugated polymers to cdse nanocrystals. Phys. Rev. B 59, 10622-10629 (1999).

21. Abrusci, A. et al. High performance perovskite-polymer hybrid solar cells via electronic coupling with fullerene monolayers. Nano Lett. 13, 3124-3128 (2013).
22. Eperon, G. E., Burlakov, V. M., Docampo, P., Goriely, A. \& Snaith, H. J. Morphological control for high performance, solution-processed planar heterojunction perovskite solar cells. Adv. Funct. Mater. http://dx.doi.org/ 10.1002/adfm.201302090 (2013).

23. Kim, J. Y. et al. New architecture for high-efficiency polymer photovoltaic cells using solution-based titanium oxide as an optical spacer. Adv. Mater. 18, 572-576 (2006).

24. He, Z. et al. Simultaneous enhancement of open-circuit voltage, short-circuit current density, and fill factor in polymer solar cells. Adv. Mater. 23, 4636-4643 (2011).

25. Goetzberger, A., Hebling, C. \& Schock, H.-W. Photovoltaic materials, history, status and outlook. Mat. Sci. Eng. R 40, 1-46 (2003).

26. Small, C. E. et al. High-efficiency inverted dithienogermolethienopyrrolodione-based polymer solar cells. Nat. Photon 6, 115-120 (2012).

27. Ishihara, T. Optical properties of pbi-based perovskite structures. J. Lumin. 60-61, 269-274 (1994).

28. McGehee, M. D. Materials science: fast-track solar cells. Nature 501, 323-325 (2013).

\section{Acknowledgements}

This project was partially funded by EPSRC and the European Community's Seventh Framework Programme (FP7/2007-2013) under grant agreement no. 246124 of the SANS project and ERC StG2013 HYPER (project reference 279881).

\section{Author contributions}

P.D. and H.J.S. conceived the experiments. P.D. carried out the initial experiments, M.D. and G.E. performed the final device optimization. J.B. carried out all the optical characterization experiments. P.D. prepared the figures and wrote the first draft of the paper All authors contributed to the writing of the paper.

\section{Additional information}

Supplementary Information accompanies this paper at http://www.nature.com/ naturecommunications

Competing financial interests: The authors declare no competing financial interests.

Reprints and permission information is available online at http://npg.nature.com/ reprintsandpermissions/

How to cite this article: Docampo, P. et al. Efficient organometal trihalide perovskite planar-heterojunction solar cells for flexible polymer substrates. Nat. Commun. 4:2761 doi: 10.1038/ncomms3761 (2013). 